\section{BMJ Global Health}

\title{
The International Diet-Health Index: a novel tool to evaluate diet quality for cardiometabolic health across countries
}

\author{
Jifan Wang (D , ,' William A Masters, ${ }^{2,3}$ Yan Bai, ${ }^{2}$ Dariush Mozaffarian, ${ }^{1}$ \\ Elena N Naumova, ${ }^{1}$ Gitanjali M Singh ${ }^{1}$
}

To cite: Wang J, Masters WA, Bai Y, et al. The International Diet-Health Index: a novel tool to evaluate diet quality for cardiometabolic health across countries. BMJ Global Health 2020;5:e002120. doi:10.1136/ bmjgh-2019-002120

Handling editor Sanne Peters

- Additional material is published online only. To view please visit the journal online (http://dx.doi.org/10.1136/ bmjgh-2019-002120).

Received 30 October 2019 Revised 22 March 2020 Accepted 15 April 2020

Check for updates

(c) Author(s) (or their employer(s)) 2020. Re-use permitted under CC BY-NC. No commercial re-use. See rights and permissions. Published by BMJ.

\section{${ }^{1}$ Division of Nutrition}

Epidemiology and Data Science, Tufts University Friedman School of Nutrition Science and Policy, Boston, Massachusetts, USA ${ }^{2}$ Division of Food and Nutrition Policy and Programs, Tufts University Friedman School of Nutrition Science and Policy, Boston, Massachusetts, USA ${ }^{3}$ Department of Economics, Tufts University School of Arts and Sciences, Medford, Massachusetts, USA

Correspondence to Dr Gitanjali M Singh; Gitanjali.Singh@Tufts.edu

\section{ABSTRACT}

Introduction Diet is a major modifiable risk factor for cardiometabolic disease; however, interpretable measures capturing impacts of overall diet on health that can be easily used by policymakers at the global/national levels are not readily available.

Methods We developed the International Diet-Health Index (IDHI) to measure health impacts of dietary intake across 186 countries in 2010, using age-specific and sex-specific data on country-level dietary intake, effects of dietary factors on cardiometabolic diseases and country-specific cardiometabolic disease profiles. The index encompasses the impact of 11 foods/nutrients on 12 cardiometabolic diseases, the mediation of health effects of specific dietary intakes through blood pressure and body mass index and background disease prevalence in each country-age-sex group. We decomposed the index into IDH $\left.\right|_{\text {beneficial }}$ for riskreducing factors, and $\mathrm{IDH}_{\text {adverse }}$ for risk-increasing factors. The flexible functional form of the IDHI allows inclusion of additional risk factors and diseases as data become available.

Results By sex, women experienced smaller detrimental cardiometabolic effects of diet than men: (females IDHI range: -0.480 (5th percentile, 95 th percentile: -0.932 , $-0.300)$ to $-0.314(-0.543,-0.213)$; males $\mathrm{IDH}_{\text {adverse }}$ range: $(-0.617(-1.054,-0.384)$ to $-0.346(-0.624,-0.222))$. By age, middle-aged adults had highest $\mathrm{IDH}_{\text {beneficial }}$ (females: 0.392 (0.235, 0.763); males: $0.415(0.243,0.949))$ and younger adults had most extreme IDHI ${ }_{\text {adverse }}$ (females: -0.480 (-0.932, -0.300); males: -0.617 (-1.054, $-0.384))$. Regionally, Central Latin America had the lowest $\mathrm{IDH}_{\text {overall }}(-0.466(-0.892,-0.159))$, while Southeast Asia had the highest IDHI ${ }_{\text {overall }}(0.272(-0.224,0.903))$. IDH ${ }_{\text {overall }}$ was highest in low-income countries and lowest in upper middle-income countries $(-0.039(-0.317,0.227)$ and $-0.146(-0.605,0.303)$, respectively). Among 186 countries, Honduras had lowest IDH ${ }_{\text {overall }}(-0.721(-0.916,-0.207))$, while Malaysia had highest IDHI ${ }_{\text {overall }}(0.904(0.435,1.190))$. Conclusion IDHI encompasses dietary intakes, health effects and country disease profiles into a single index, allowing policymakers a useful means of assessing/comparing health impacts of diet quality between populations.

\section{INTRODUCTION}

Cardiometabolic disease, including cardiovascular disease (CVD) and diabetes, is the

\section{Key questions}

\section{What is already known?}

- Diet is a key modifiable risk factor for cardiometabolic disease, which causes enormous morbidity and mortality worldwide.

- Comprehensive and interpretable evidence is critical to the informed development of dietary policy and intervention to combat global cardiometabolic burdens.

- Numerous dietary and global health indices exist; however, none simultaneously links quantitative information on multiple dietary components and health in a single comprehensive metric for efficient use by policymakers in cross-population global comparisons.

\section{What are the new findings?}

- Here we report development and application of the International Diet-Health Index (IDHI), which simultaneously encompasses data on multiple dietary exposures, their health effects and population disease profiles in a single metric.

- Calculation of IDHI across 186 countries worldwide indicates a net adverse cardiometabolic impact from diet worldwide, with significant demographic and geographic variations.

What do the new findings imply?

- The IDHI highlights the progress of the nutrition transition across the world and emphasises its impact on middle-income countries and younger populations, indicating key targets for policymakers.

- The IDHI presents a novel and useful means for global policymakers to evaluate cardiometabolic impacts of diet at the country and regional levels, by age and sex, to develop appropriately targeted interventions to limit consumption of dietary factors that increase cardiometabolic risk and to promote consumption of foods and nutrients that reduce cardiometabolic risk, given a country's demographic and disease profile.

- As additional data become available, the IDHI has a sufficiently flexible functional form so that it can further be extended to incorporate relationships between diet and undernutrition to effectively measure double burdens of disease, making it particularly relevant to policymakers in middle-income countries. 
largest cause of death and disability worldwide, resulting in $33 \%$ of deaths globally in $2016 .{ }^{12}$ Diet is a key modifiable risk factor for cardiometabolic disease, and assessing population-wide impacts of diet as a whole on health is critical to developing strategies to curb significant cardiometabolic burdens; however, diet is a multifactorial component of lifestyle with complex effects on multiple disease pathways. ${ }^{3}$ Development of a standard global index linking diet and disease, while taking into consideration the differing distributions of disease across populations, can generate a useful and interpretable tool for global and regional policymakers to assess the health effects of diet efficiently and effectively.

Numerous diet quality indices currently exist, but none explicitly identify which disease outcomes are affected by intake of each food and cannot be generalised beyond particular populations, specific outcomes and target dietary patterns. The Healthy Eating Index (HEI) assesses individual adherence to the American Dietary Guidelines ${ }^{4}$; the Alternative Healthy Eating Index (AHEI) focuses on a specific dietary pattern that considered protective against chronic diseases ${ }^{5}$; the Mediterranean Diet Score (MDS) ${ }^{67}$ and its modifications ${ }^{8-11}$ indicate compliance to Mediterranean diet, but generalisability and application to global populations remain limited. The Diet Quality Index-International, developed for cross-country diet quality comparisons, considers food variety, diet adequacy, nutrient density and overall balance of diet. ${ }^{12}$ Additional recent work with global coverage has also assessed diet quality across countries of the world and over time. ${ }^{13}$ However, these indices typically have a predefined reference diet, and none of them evaluates the health effects of diet while also taking into consideration the varied distributions of disease across populations.

Analogously, several indices assessing global crosspopulation health status exist, incorporating countrylevel data on health metrics; however, such indices often do not incorporate quantitative aetiological data linking risk factors and health outcomes. The Bloomberg Global Health Index provides health grades for 169 countries using life expectancy, mortality data and exposure to behavioural and environmental factors in each country ${ }^{14}$; similarly, the United Nations Development Program (UNDP) converts life expectancy into the UNDP Health Index for about 190 countries. ${ }^{15}$ A few global health indices focus on nutrition or nutrition-related outcomes, including the Global Hunger Index, developed by the International Food Policy Research Institute and revised by the United Nations, which is composed of the prevalence of undernourishment, child wasting, child stunting and child mortality before the age of 5 years. ${ }^{16}$ Similarly, the Global Nutrition Index incorporates protein-energy and micronutrient deficiency, obesity and food security into the index to estimate the overall nutritional status for 192 countries. ${ }^{17}$

Additional recent global studies have assessed the health effects of diet. The Global Burden of Disease
Project (GBD) estimates the risk-weighted exposure level of individual environmental, behavioural and metabolic risk factors, including 16 dietary components, and aetiological effects of risk factors on disease outcomes but does not estimate the simultaneous health effects of all dietary components, which is important given that all dietary factors are consumed in tandem. ${ }^{18} 19$ Further efforts to evaluate the health effects of total diet at the global level have focused on mortality but not specifically on overall cardiometabolic health impacts. ${ }^{20}$ Recently, Wang $e t a l^{21}$ carried out a global dietary quality assessment, applying AHEI to global data and estimated dietary-attributable premature deaths due to chronic disease; similarly, Sezaki $e t a l^{22}$ investigated the association between MDS and incidence of ischaemic heart disease (IHD) globally. ${ }^{22}$ However, both studies rely on prespecified dietary patterns and do not incorporate effects on both deaths and disability, separately evaluate risk-reducing and risk-increasing components of diet or provide detailed country-specific, age-specific and sex-specific results.

Here we report a novel International Diet-Health Index (IDHI) that allows cross-population assessment of the cardiometabolic health effects of overall diet, including both risk-reducing and risk-increasing dietary factors, without relying on prespecified dietary patterns. This methodology incorporates country-specific, age-specific and sex-specific data on dietary intakes, metabolic mediators, aetiological effects and populationspecific cardiometabolic disease profile, to generate a standardised and comparable index evaluating health effects of overall diet across different populations globally to inform appropriate dietary policy and intervention worldwide.

\section{METHODS}

\section{Data sources}

Here we assess the impact of diet on cardiometabolic disease in 186 countries based on data from four primary sources (table 1): (1) dietary intake distributions of 11 commonly consumed dietary factors by country, age and sex from the Global Dietary Database (GDD), ${ }^{23}(2)$ agespecific relative risks of cardiometabolic outcomes per unit of each dietary factor or metabolic mediator from meta-analyses of data from prospective cohort studies or randomised trials, ${ }^{2425}$ (3) country-specific, age-specific and sex-specific mean body mass index (BMI), mean systolic blood pressure (SBP), and the prevalence of hypertension from the from the Non-Communicable Disease Risk Factor Collaboration (NCD-RisC) ${ }^{26}$ and (4) country-specific, age-specific and sex-specific disabilityadjusted life years (DALYs) for cardiometabolic diseases from the Global Health Data Exchange (GHDx). ${ }^{27}$

Briefly, energy-adjusted national dietary intake in 2010 was obtained from GDD, which collected, compiled and aggregated national or subnational surveys in 186 countries by country, age and sex. ${ }^{28}{ }^{29}$ We used data on dietary intakes of fruits, vegetables, nuts and seeds, whole grains, 
Table 1 Table of data source and description

\begin{tabular}{|c|c|c|}
\hline Input & Source & Description \\
\hline Dietary intakes & Global Dietary Database ${ }^{23}$ & $\begin{array}{l}\text { Age-specific and sex-specific energy-adjusted dietary intakes } \\
\text { of } 11 \text { dietary factors in } 188 \text { countries. }{ }^{*} \\
\text { Data from national and subnational population-based surveys. }\end{array}$ \\
\hline Metabolic mediators & $\begin{array}{l}\text { Non-Communicable Disease } \\
\text { Risk Factor Collaboration } \\
65\end{array}$ & $\begin{array}{l}\text { Age-specific and sex-specific mean of BMI and SBP and } \\
\text { prevalence of hypertension in } 191 \text { countries in } 2010 . \dagger \\
\text { Data from national and subnational population-based surveys. }\end{array}$ \\
\hline $\begin{array}{l}\text { Relative risks for dietary and } \\
\text { metabolic mediator impact on } \\
\text { disease }\end{array}$ & Published meta-analyses 2425 & $\begin{array}{l}\text { Age-specific relationships between dietary factors and } \\
\text { diseases, dietary factors and metabolic mediators, and } \\
\text { mediators and diseases from prospective cohorts and } \\
\text { randomised clinical trials. } \neq \\
\text { Thirty-six diet-disease pairs are available. }\end{array}$ \\
\hline DALYs & $\begin{array}{l}\text { Global Health Data } \\
\text { Exchange }^{27}\end{array}$ & $\begin{array}{l}\text { Age-specific and sex-specific DALYs for } 12 \text { cardiometabolic } \\
\text { diseases in } 195 \text { countries in } 2010 . \S \\
\text { DALYs comprise both years of life lost and years lived with } \\
\text { disability. }\end{array}$ \\
\hline Population & $\begin{array}{l}\text { Global Health Data } \\
\text { Exchange }\end{array}$ & $\begin{array}{l}\text { Number of people for each age-specific, sex-specific and } \\
\text { country-specific category in } 196 \text { countries in } 2010.9\end{array}$ \\
\hline
\end{tabular}

*Data were available from 20 to $80+$ years old by 5-year age intervals. Age groups in other data sources were adjusted to match the age groups in the dietary intake data.

†Data were available from 25 to $85+$ years old by 5-year age intervals. In accordance with the dietary intake data, groups of 80-84 years and over 85 years were collapsed to the group of over 80 years by population weighting.

¥Data were available from 25 to $75+$ years old by 5-year age intervals. In accordance with the dietary intake data, the age groups of 75-79 years and over 80 years were created using the data from group of $75+$ years old.

$\S$ Data were available from 1 to $80+$ years old by 5 -year age intervals originally. Only age groups above 25 years old were used in this analysis.

IPopulation estimates for men and women were available from 0 to 104 years old by 5 -year age intervals for 196 countries. Total population for both sexes were calculated by summing up the sex-specific data in each country-age group.

BMI, body mass index; DALYs, disability-adjusted life years; SBP, systolic blood pressure.

processed meat, red meat, polyunsaturated fatty acids (PUFAs), saturated fatty acids (SFA), seafood omega 3, sugar-sweetened beverages (SSB) and dietary sodium (online supplementary table 1 ). While these 11 dietary factors do not capture the totality of diet, they are the best dietary intake data on widely consumed foods and nutrients that are available for 186 countries by age and sex. As dietary intake data on additional foods and nutrients become available for all country-age-sex groups, the IDHI has been designed to be sufficiently flexible enough to incorporate them. The serving sizes of each dietary factor are specified in online supplementary table 1 and were selected based on serving sizes used in reports of aetiological effects of diet on disease outcomes. ${ }^{24}$ Data were provided by sex and 5-year age interval for adults aged $25+$ years.

Dose-response relative risks for cardiometabolic diseases per-unit increase in each dietary factor were based on a published meta-analysis reporting age-specific effects for each diet-disease pair with probable or convincing evidence of causal effect based on evaluation of Bradford Hill criteria. ${ }^{24}$ Outcomes included were: ischaemic heart disease (International Classification of Diseases, 10th Revision codes I20-I25), ischaemic stroke (I63, I65-I67 (except I67.4) and I69.3), haemorrhagic stroke (I60-I62, I69.0-I69.2 and I67.4), atrial fibrillation and flutter (I48), aortic aneurysm (I71), hypertensive heart disease (I11), endocarditis (I33), peripheral artery disease (I73 and I70.2), cardiomyopathy and myocarditis (I42 and I40), rheumatic heart disease (I01, I02.0 and I05-I09), type 2 diabetes mellitus (E11 (except E11.2)) and other cardiovascular and circulatory diseases (I00, I02.9, I27-I28 (except I27.1), I30-I32 (except I31.2 and I31.3), I34-I39, I47, I70.8, I72, I77-I80, I82-I84 and I86-I98). For SSBs, both the direct and BMI-mediated effects on cardiometabolic disease were included, accounting for heterogeneity in effects of SSB on BMI for overweight (BMI $\geq 25$ ) versus non-overweight populations. ${ }^{24}$ For sodium, all cardiovascular effects were mediated through systolic blood pressure (SBP), and heterogeneity in the effects of sodium on SBP by age, race and hypertensive status were included in the estimation process. ${ }^{24}{ }^{30}$ Effects of BMI and SBP on cardiometabolic disease were obtained from a large pooling project of international prospective cohort studies. ${ }^{25}$ Mean BMI, mean SBP, and the prevalence of hypertension in 191 countries by age and sex were obtained from NCD-RisC. DALYs for 12 cardiometabolic diseases were downloaded from GHDx for 195 countries in 12 age groups and 3 sex groups (female, male and both), as was global population data for 2010. We followed the Guidelines for Accurate and Transparent Health Estimates Reporting (GATHER) checklist to present the data sources and results in the current study and provide details in online supplementary table 2. 


\section{Statistical analysis}

Calculation of the IDHI

The IDHI assesses impact of diet on cardiometabolic health among adults aged 25 years and over by age and sex in 186 countries in the world. Dietary intakes of 11 foods and nutrients are weighted by the relative influence of each dietary factor on disease outcomes and the proportional contribution of each disease to the overall cardiometabolic burden in each country-age-sex group. For each country-age-sex group, the IDHI ${ }_{\text {overall }}$ is defined as:

$$
\begin{aligned}
\text { IIDHI }_{\text {overall }}= & \sum_{k=1}^{12}\left\{\sum_{j=1}^{10}\left[\text { Intake }_{j} \times\left(-\ln R R_{j k}\right) \times\left(\frac{D A L Y_{k}}{\sum_{k=1}^{12} D A L Y_{k}}\right)\right]\right. \\
& \left.+\sum_{i, j=1}^{2}\left[\left(\text { Intake }_{j} \times \beta_{i j}\right) \times\left(-\ln R R_{j k}\right) \times\left(\frac{D A L Y_{k}}{\sum_{k=1}^{12} D A L Y_{k}}\right)\right]\right\}
\end{aligned}
$$

where Intake ${ }_{j}$ is the group's average daily intake of dietary factor $j ; \operatorname{lnRR}_{j k}$ is the natural logarithm of relative risk per unit of intake for dietary factor $j$ on the incidence of disease $k$ in that population group; $\mathrm{DALY}_{k}$ is the total DALYs incurred by the group from disease $k ; \beta_{i j}$ is the linear effect between mediator $i$ and dietary factor $j$, which varies by age, race and hypertensive status for the effects of sodium on SBP and by overweight status for the effects of $\mathrm{SSB}$ on $\mathrm{BMI} ; \operatorname{lnRR}{ }_{i k}$ is the $\log$ relative risk between mediator $i$ and disease $k$ per unit change in mediator $i$ (online supplementary figure 1 ). The negative natural logarithm of the RR was used to improve interpretability of the index such that positive values indicate ameliorative health effects and negative values indicate detrimental health effects. Overall, 11 dietary factors, 12 diseases and 2 mediators (BMI and SBP) were included in our analysis; 10 dietary factors have direct influence on diseases, and two dietary factors have effects mediated by BMI or SBP. SSB has both direct effect and mediated effect (by BMI) on diabetes and ischaemic heart disease. This results in a total of 20 diet-disease pairs in which diet directly impacts disease and 16 diet-mediator-disease pathways in which the dietary impact on disease is mediated through either SBP or BMI (figure 1). Countryage-sex specific IDHIs were weighted by the population in each age group to obtain overall country-level IDHIs by sex. Regional, super-regional and global IDHIs were calculated as the population-weighted means of countryage-sex specific IDHIs.

\section{Calculation of IDHI ${ }_{\text {beneficial }}$ and IDHI $\left.\right|_{\text {adverse }}$}

Prior studies have indicated that there is significant geographic heterogeneity in consumption of healthful and unhealthful dietary components globally. ${ }^{13}$ In order to separately assess the health effects of risk-reducing and risk-increasing dietary factors, in addition to calculating the IDHI ${ }_{\text {overall }}$, which captures total diet, we calculated the IDHI $_{\text {beneficial }}$ and IDHI ${ }_{\text {adverse }}$, using equations analogous to those in online supplementary figure 1 . The IDHI $_{\text {benefi- }}$ cial is based on risk-reducing dietary factors: fruits, vegetables, nuts and seeds, whole grains, PUFA and seafood omega 3; similarly, the IDHI ${ }_{\text {adverse }}$ is calculated based on risk-increasing dietary factors, that is, processed meat, red meat, SFA, SSB and sodium.

Based on the maximum and minimum values of the data inputs we used in the current study, the IDHI $_{\text {bene- }}$ ficial can theoretically range from 0.001 to 16.087 at the country-age-sex level, with greater positive values indicating healthful cardiometabolic impacts from diet. The empirical bounds of $\mathrm{IDHI}_{\text {beneficial }}$ estimated using the data and methodology described above are 0.090 (lower bound) to 2.156 (upper bound). Mirroring this, the $\mathrm{IDHI}_{\text {adverse }}$ can theoretically range from -0.002 to -11.526 , based on the minimum and maximum inputs, with larger negative values indicating more adverse impacts on the health outcomes of interest while the empirical bounds

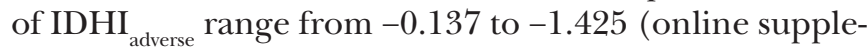
mentary table 3 and online supplementary figure 2).

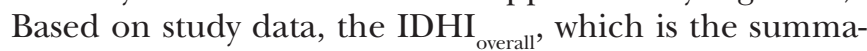
tion of IDHI $_{\text {beneficial }}$ and IDHI ${ }_{\text {adverse }}$, is bounded between -1.032 and 1.368 , although the theoretical range based on minimum and maximum input values could range from -11.525 to 16.086 (online supplementary table 3 and online supplementary figure 3 ). The distributions

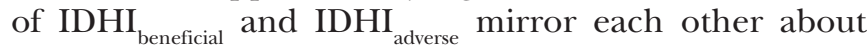
zero and the distribution of IDHI ${ }_{\text {overall }}$ is nearly symmetric (online supplementary figures 2 and 3 ).

Analyses were conducted at the country-age-sex level and were aggregated into country-level, regional-level or global-level estimates through population weighting. Countries were classified into 21 regions and 9 superregions based on previously described classification schemes (online supplementary table 4 ) ${ }^{31}$ Countries were categorised into income groups based on the 2017 World Bank classification system. ${ }^{32}$ Data cleaning, merging and visualisation were conducted using R V.3.5.1.

\section{Patients and public involvement}

No patients were involved in this study.

\section{RESULTS \\ Global distributions of the IDH}

Globally and across age groups, the range of IDHI was smaller among women than among men for the overall, beneficial and adverse IDHIs (table 2). The IDHI ${ }_{\text {overall }}$ ranged from -0.986 to 0.954 across age groups in women and from -1.032 to 1.368 across age groups in men, indicating a smaller impact of overall diet on cardiometabolic health among women than among men, globally. The $\mathrm{IDHI}_{\text {beneficial }}$ ranged from 0.102 to 1.528 in women and from 0.090 to 2.156 in men. The IDHI $_{\text {adverse }}$ ranged from -1.230 to -0.154 in women and from -1.425 to -0.137 in men. Risk-reducing dietary factors had the greatest beneficial impact on middle-aged populations and the smallest impact on the elderly ( $>70$ years), whereas the deleterious impact of risk-increasing dietary factors on cardiometabolic health was greatest among younger age 


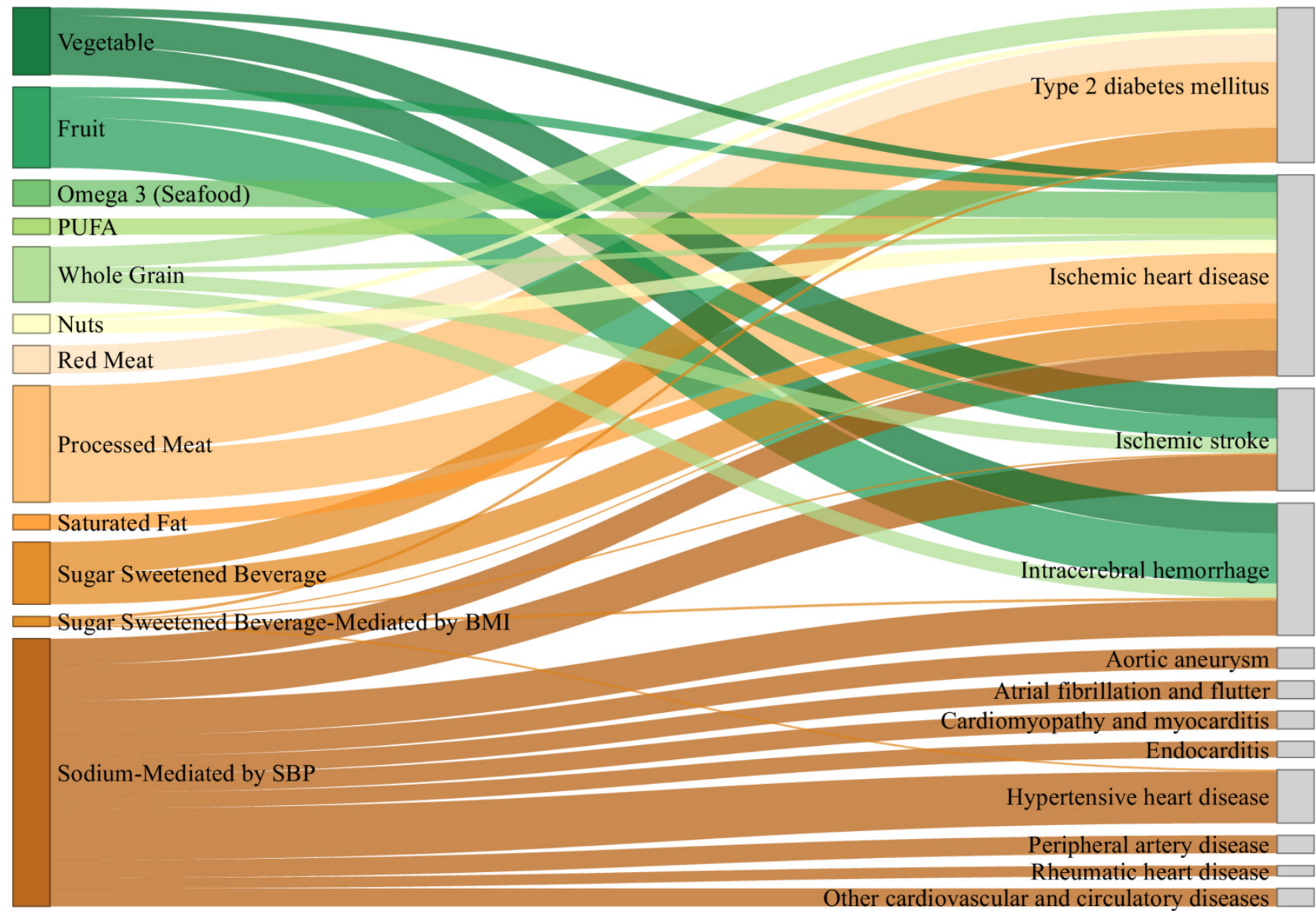

Figure 1 Relationships between dietary factors, metabolic mediators and disease outcome in the International Diet-Health index (IDHI). This Sankey diagram provides an overview of the relationships between dietary factors, metabolic mediators and disease outcomes that are included in the IDHI calculations, and it is based on the epidemiological relative risks data that are used in this analysis and that were obtained from published sources. The thickness of lodes (connections between risk factors and disease outcomes) represents the relative magnitude of aetiological effect of each dietary factor on disease per serving of each dietary factor. For effects mediated by BMI or SBP, the lodes were calculated as the products of linear effects of the dietary factor on the mediator and the effects of the mediator on the disease. There are 20 direct effects of dietary factors on cardiometabolic diseases, 5 indirect effects of sugar-sweetened beverages mediated by BMI and 11 indirect effects of sodium mediated by SBP. BMI, body mass index; PUFA, polyunsaturated fatty acids; SBP, systolic blood pressure.

groups and declined with age. Similar trends in age can also be observed at the super-regional level (figure 2).

\section{Regional distributions of the IDHI}

At the regional level, Central Latin America had the lowest IDHI ${ }_{\text {overall }}-0.466$ (5th percentile, $95^{\text {th }}$ percentile: $-0.892,-0.159)$, while Southeast Asia had the highest IDHI $_{\text {overall }} 0.272(-0.224,0.903)$ (table 2$)$. Southern SubSaharan Africa had the lowest IDHI ${ }_{\text {beneficial }}$ of $0.229(0.118$, 0.324), while Southeast Asia had the highest IDHI $_{\text {benefi- }}$ cial of $0.797(0.308,1.484)$. Greatest (ie, most negative) IDHI $_{\text {adverse }}$ was $-0.785(-1.225,-0.341)$ in Central Latin America and the lowest (ie, least negative) $\mathrm{IDHI}_{\text {adverse }}$ was $-0.381(-0.510,-0.229)$ in South Asia.

By World Bank country income group, IDHI ${ }_{\text {overall }}$ was highest in low-income countries and lowest in upper middle-income countries $(-0.039(-0.317,0.227)$ and $-0.146(-0.605,0.303)$, respectively). Low-income countries had the lowest IDHI $_{\text {beneficial }}(0.350(0.152,0.679))$ and high-income countries had the highest IDHI $_{\text {benefi- }}$ $(0.397(0.194,0.931))$. The $\mathrm{IDHI}_{\text {adverse }}$ ranged from $-0.537(-0.953,-0.264)$ in upper middle-income countries to $-0.424(-0.633,-0.225)$ in low-income countries.

Country-level IDHI distributions by age and sex

Among 186 countries, Honduras had the lowest IDHI verall $(-0.721(-0.916,-0.207))$, while Malaysia had the highest IDHI $_{\text {overall }}(0.904(0.435,1.190))$. The IDHI beneficial was smallest in Zimbabwe $(0.160 ; 95 \%$ CI 0.098 to 0.203$))$ and largest in Malaysia (1.529 (0.788, 1.904]). Rwanda and Colombia had the smallest $(-0.246(-0.286,-0.162))$ and greatest $(-1.079(-1.275,-0.435))$ IDHI $_{\text {adverse }}$, respectively (online supplementary table 5 , figure 3 ).

At the country level, by age, the lowest IDHI overall $_{\text {was }}$ $-0.881(-0.987,-0.740)$ among adults aged $25-44$ years in Trinidad and Tobago, while the highest IDHI overall $_{\text {was }}$ $1.131(0.966,1.227)$ in adults $45-69$ years old in Malaysia. People over 70 years of age in Zimbabwe had the lowest 
$\mathrm{IDHI}_{\text {beneficial }}(0.128(0.098,0.158))$, and people between 45 and 69 years old in Malaysia had the highest IDHI $_{\text {ben- }}$ eficial $(1.782(1.524,1.928))$. For IDHI $_{\text {adverse }}$, the lowest (ie, most adverse) was observed among younger Colombian adults, aged $25-44$ years old $(-1.243(-1.315,-1.186))$ and the highest (ie, least adverse) was among persons over 70 years of age in Rwanda $(-0.207(-0.252,-0.151))$. In general, the IDHI ${ }_{\text {overall }}$ and IDHI adverse $_{\text {approach } 0 \text { with }}$ increasing age in most countries, while $\mathrm{IDHI}_{\text {beneficial }}$ was generally highest in the 45-69 years age group and lowest at ages over 70 years (figure 4 ).

\section{Proportional composition of IDHI by dietary factor across super- regions}

Relative contributions of each dietary factor in each super-region to the $\mathrm{IDHI}_{\text {overall }}$ are reported in figure 5 . Variation is evident in proportional contributions of risk-reducing dietary factors to $\mathrm{IDHI}_{\text {overall }}$ in each superregion: no single risk-reducing dietary factor contributed most across super-regions; however, nuts contributed least to the index in most super-regions. Across superregion, sodium was the risk-increasing dietary component with greatest proportional contribution to the IDHI $_{\text {overall }}$ except in Latin America and the Caribbean, where SSB contributed the greatest proportion. Among risk-increasing factors, red meat generally contributes the smallest proportion to the IDHI ${ }_{\text {overall }}$.

\section{DISCUSSION}

Here we report the development and application of a new global index, the IDHI, which provides a comparable and interpretable means of comprehensively evaluating the cardiometabolic impacts of overall diet, as well as risk-reducing and risk-increasing dietary components, at the global, regional and national levels. We found that globally, women experienced smaller detrimental cardiometabolic effects of diet than men; risk-increasing dietary components had greater negative cardiometabolic impacts on younger adults than older adults, while risk-reducing dietary factors had greater impact on middle-aged adults; upper middle-income countries experienced the greatest cardiometabolic impacts of overall diet, and significant geographic heterogeneity was evident in overall dietary impacts on cardiometabolic health, based on data from 2010.

Key similarities in findings between our study and prior investigations should be noted, particularly congruencies in patterns by income group and sex. The strength and importance of these findings is emphasised by the fact that they result from studies using varied methodologies. Prior efforts have evaluated the health effects of diet in global settings ${ }^{20-22} 3033$ 34; of those, a few have focused on overall diet instead of single dietary factors. ${ }^{20-22}$ One study estimated dietary-attributable all-cause and cause-specific deaths and DALYs using joint population attributable fractions. ${ }^{20}$ Another evaluated the number of premature chronic disease deaths that would be prevented if the 


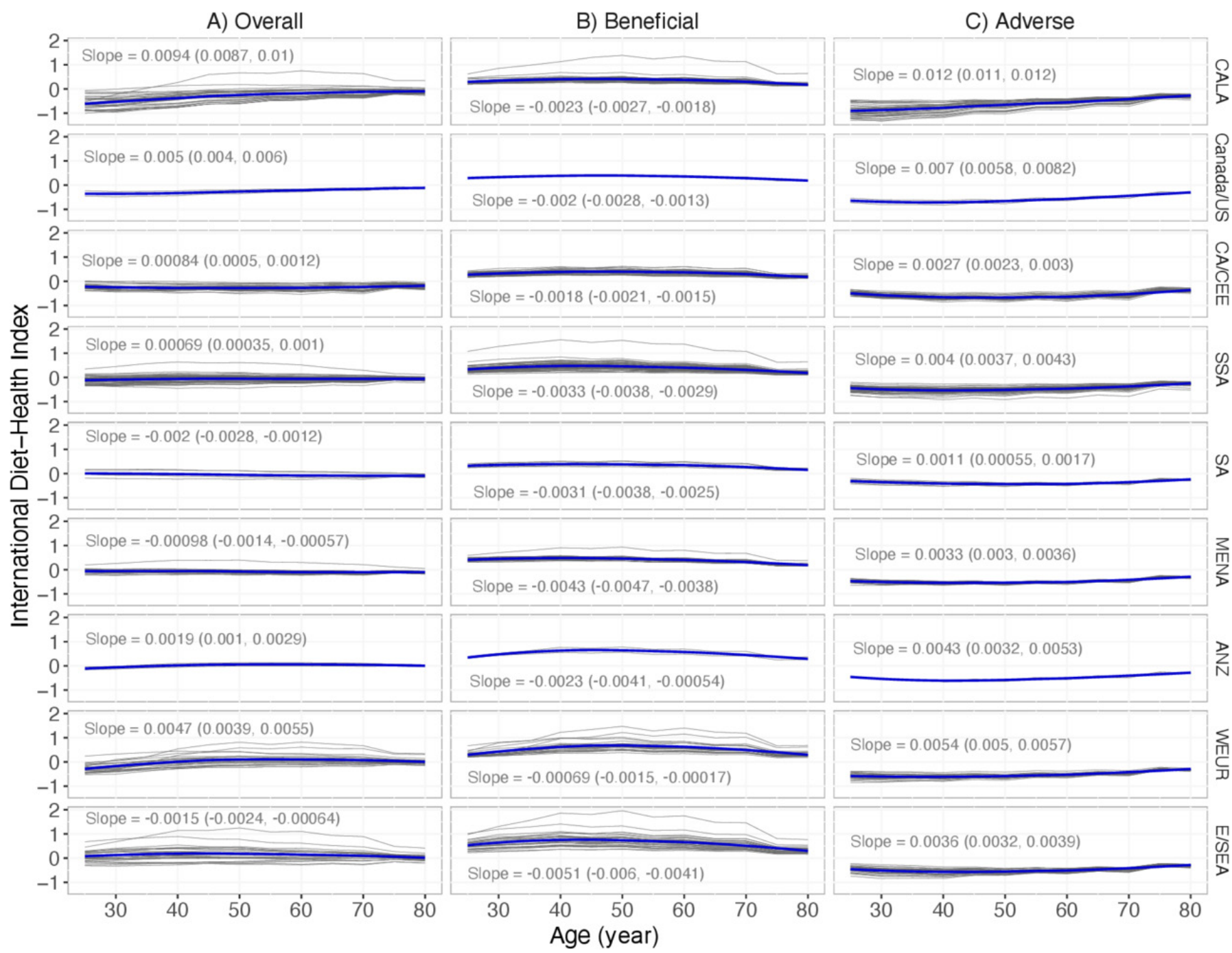

Figure 2 Age distribution of the International Diet-Health Index by super-regions for: (A) IDHI overall, (B) IDHI beneficial, (C) IDHI adverse. The thick blue line shows the Loess curve of the relationship between age and IDHIs in each super-region. Light grey lines represent the relationship between age and IDHI for each country in each super-region and are shown only to indicate the variability of trends within each super-region. Slopes of linear regressions between age and IDHI in each super-region are indicated to show whether there is positive, negative or null relationship between age and each IDHI score. Regression slopes represent the change in IDHI per year of age, as the starting point of each 5-year age group was used as the independent variable. ANZ, Australia and New Zealand; CA/CEE, Central Asia/Eastern and Central Europe; CALA, Latin America and Caribbean; E/SEA, East and Southeast Asia; MENA, North Africa and middle East; SA, South Asia; SSA, SubSaharan Africa; WEUR, Western Europe.

global population followed the EAT-Lancet $\operatorname{diet}^{35}$ using AHEI. $^{21}$ A third assessed the adherence to Mediterranean diet in 132 countries using MDS and evaluated the association between MDS and IHD incidence adjusting socioeconomic and lifestyle factors. ${ }^{22}$ Some methodological differences exist between these studies, including the source of dietary and aetiological effects data, outcomes included and statistical models used, yet the similarity in key findings is notable.

Geographically, Southeast Asian countries achieved greatest overall diet-related cardiometabolic benefits, while Central Latin America countries experienced greatest negative cardiometabolic impact from overall diet. Countries in Southeast Asia attained the most cardiometabolic protection from healthful dietary components; South Asian countries experienced the least cardiometabolic harms from unhealthful dietary components. Countries in Southern Sub-Saharan Africa gained the least cardiometabolic benefits from healthful dietary factors, possibly related to region-specific dietary patterns and the continued double burden of both cardiometabolic disease and disease related to undernutrition. ${ }^{36}$ Central Latin American countries experienced greatest cardiometabolic harms from overall diet as well as unhealthful dietary factors, findings that are in line with prior work indicating that this region was among world regions with greatest diet-related diabetes mortality and morbidity. ${ }^{20}$ East Asia, high-income AsiaPacific and Australasia were among regions with higher $\mathrm{IDHI}_{\text {overall }}$ in our study, indicating that they derived greater 
A) IDHI overall

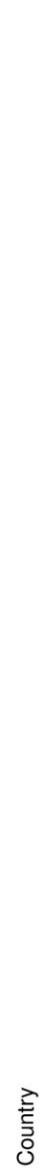

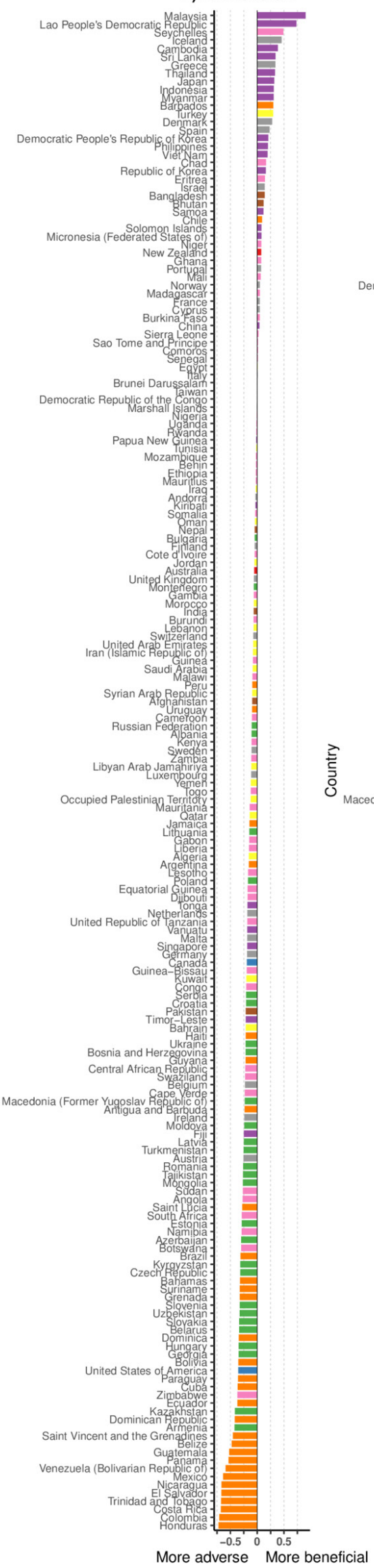

B) IDHI beneficial

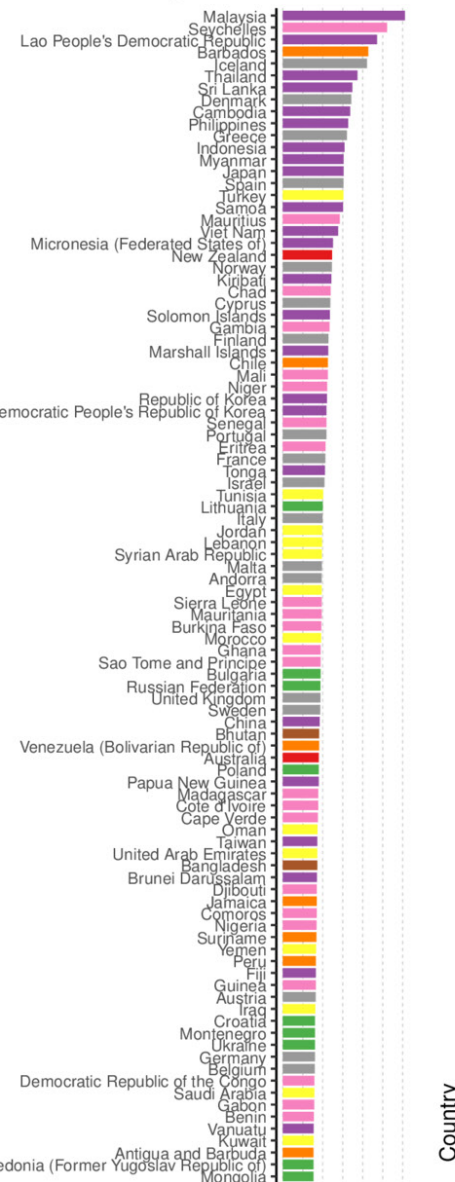

홍

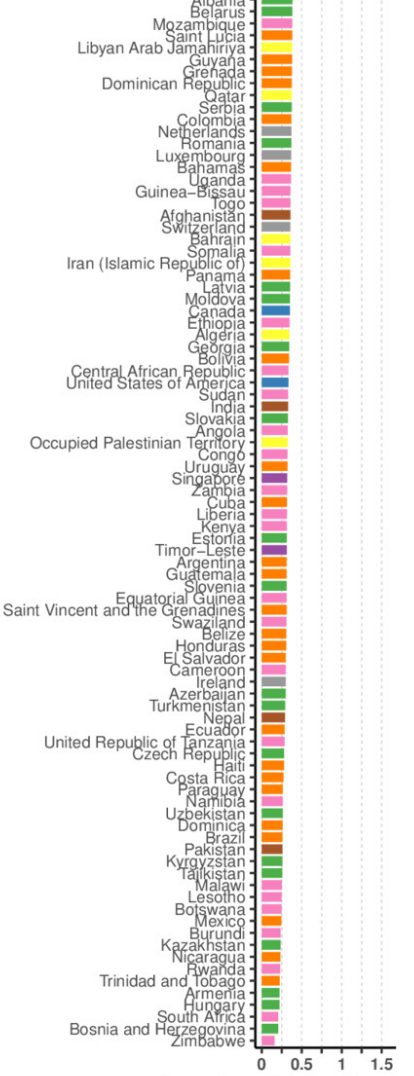

Less beneficial More beneficial

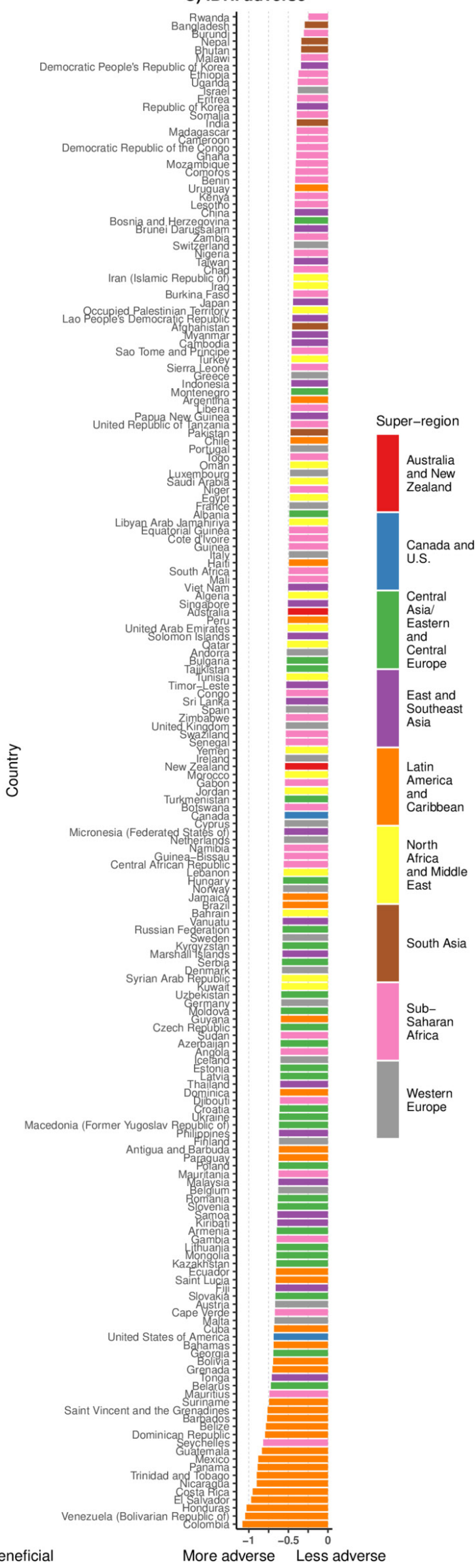

C) IDHI adverse

Figure 3 Ranking of countries by (A) IDHI overall, (B) IDHI beneficial and (C) IDHI adverse, colour-coded by super-regions. IDHI, International Diet-Health Index. 

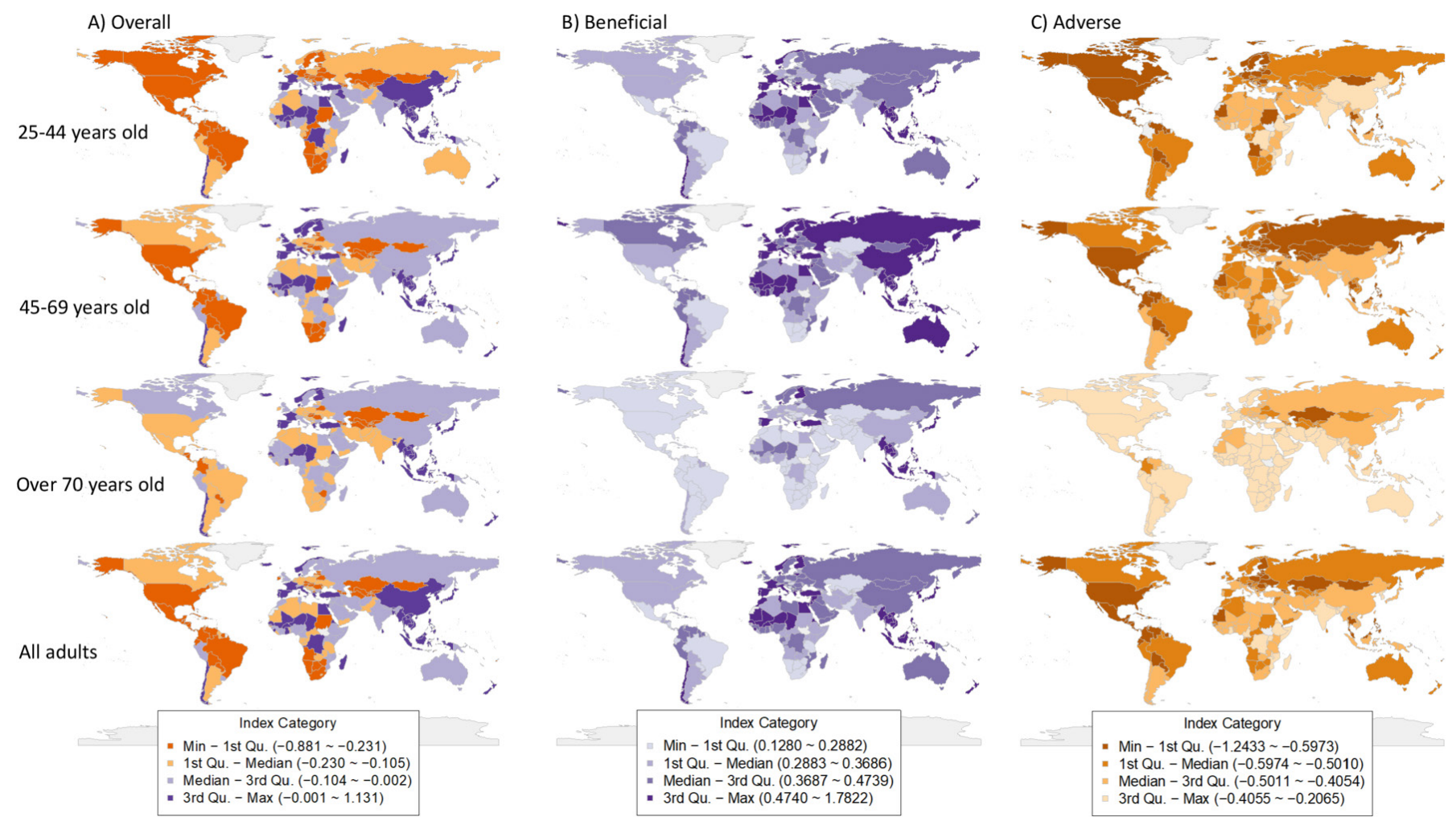

Figure 4 Global distribution of the International Diet-Health index (IDHI) by age group and across ages for (A) IDHI overall, (B) IDHI beneficial, (C) IDHI adverse. The three columns in this figure represent IDHI overall, beneficial and adverse estimates. Each world map within each column shows the country-specific IDHI for each of three age groups (25-44, 45-69 and 70+ years) and for all adults $25+$ years. By looking down each column of maps, the age trend of IDHI $\left.\right|_{\text {overall }}, I D H_{\text {beneficial }}$ and IDHI $I_{\text {adverse }}$ can be visualised by noting the differences in the colour scale of each country. The maps are colour-coded based on quartiles of each IDHI distribution, for example, for IDHI ${ }_{\text {overal, }}$ the smallest (most adverse) IDHIs are shown in orange, while the largest (most beneficial) are shown in purple. For IDHI (most beneficial) is shown in dark purple. For IDHI adverse, the smallest (most adverse) is shown in orange, while the largest (least adverse) is shown in orange. IDHI, International Diet-Health Index

cardiometabolic benefits from diet compared with other regions; these findings also reflect other work that indicated that these regions had lower diet-related CVD and diabetes mortality and morbidity. ${ }^{20}$

By national-income level, we found that populations in low-income countries experienced both a smaller beneficial effect and a smaller adverse effect of diet on cardiometabolic health and had the highest IDHI ${ }_{\text {overall }}$ across income levels. Populations in high-income countries experienced both greatest cardiometabolic protection from healthful dietary components and greatest cardiometabolic harms from unhealthful food, while upper middle-income countries had the lowest IDHI ${ }_{\text {overall' }}$, indicating greatest cardiometabolic harms from overall diet. These results mirror earlier observations made by Imamura $e t a l^{13}$ of greater consumption of healthful foods among high-income countries and least consumption of unhealthy foods in low-income countries. These findings are further supported by results from GBD $2017^{20}$ indicating greatest protection from healthy food in high-income countries and are further corroborated by data from Wang $e t a l^{21}$ indicating lowest consumption of both healthy and unhealthy dietary factors in lowincome countries.
In low-income and middle-income countries, prior studies have indicated that transition towards diets characterised by greater consumption of sugars, sodium, refined grains and animal source foods as well as lower intakes of vegetables, nuts/seeds and whole grains has played critical role in the epidemic of obesity, diabetes and other chronic disease. ${ }^{38-43}$ In our current findings, it is notable that overall diet, as measured here using 11 dietary factors, had net adverse cardiometabolic health effects at all income levels, which may be related to trends observed in other studies regarding increased global marketing and availability of processed food such as SSBs and processed meats ${ }^{44-48}$; exploration of these relationships is beyond the scope of the current work but warrants further study.

Our findings indicate an important effect of sex and age on the cardiometabolic effects of diet. We observed more favourable cardiometabolic health effects from diet among women than among men, similar to previous reports. ${ }^{13}$ Generally, risk-reducing dietary factors had largest influence on middle-aged populations and smallest influence on older populations while the impact of risk-increasing dietary factors decreased as age increased, perhaps related to less consumption of 


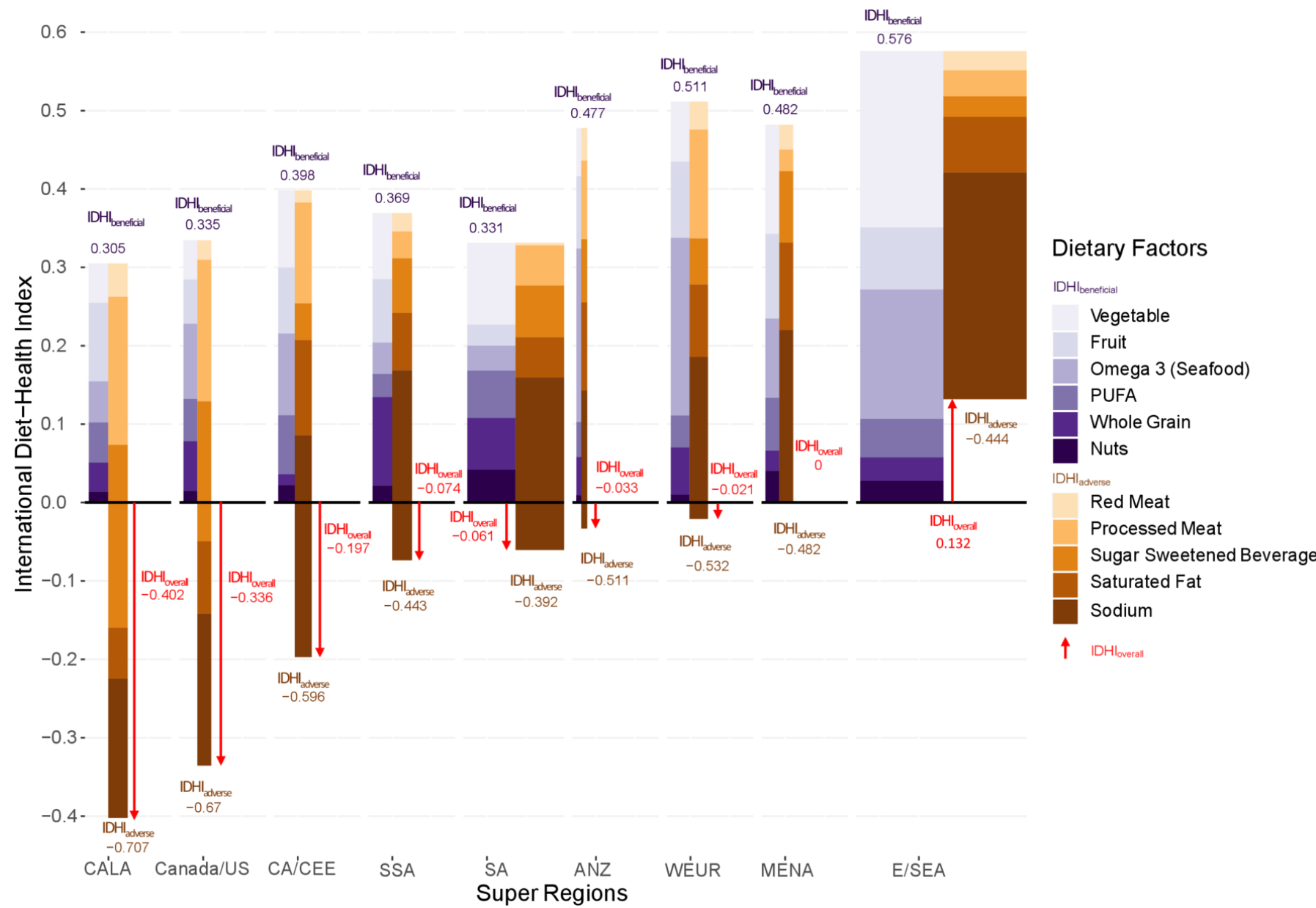

Figure 5 Mean IDHI by super-region and dietary factor, indicating the contribution of each dietary factor to the overall IDHI in each super-region. This figure depicts the contribution of each dietary factor to the IDHI. The numbers in red indicate the population-weighted IDHI overall, which is calculated as the sum of the IDHI beneficial (shown in green at the top of each bar) and the IDHI adverse (shown in brown at the bottom of each bar) numbers at the top and bottom of each bar. The width of bars is weighted by the populations in each super-region; due to low relative population counts in the ANZ region, a multiplier of 5 was applied to the population in this region in order for the bar to be visible. ANZ, Australia and New Zealand; CA/CEE, Central Asia/Eastern and Central Europe; CALA, Latin America and Caribbean; E/SEA, East and Southeast Asia; MENA, North Africa and Middle East; PUFA, polyunsaturated fatty acids; SA, South Asia; SSA, Sub-Saharan Africa; WEUR, Western Europe.

unhealthy foods, such as SSBs, processed meat and foods that are high in sodium among the elderly in many parts of the world. ${ }^{1349-51}$

The current study strengthens a growing body of global evidence that diet is of critical importance to population health and complements the findings of several large recent global studies. ${ }^{20-22}$ Despite differences in methodology and data sources, in combination, these investigations highlight that demographically and regionally targeted dietary policies are crucial to global public health targets, such as the WHO $25 \times 25$ goals. ${ }^{52}$ The success of current policy-based dietary interventions has set a positive precedent for future public health initiatives; for example, SSB taxes in Mexico, Barbados, Chile and some localities of the USA have resulted in declines in SSB purchase or consumption $^{53-56}$; similarly, reductions in energy-dense food purchase in Mexico have been observed after the tax on junk food was implemented, ${ }^{57}$ and population-based salt reduction programmes successfully reduced sodium consumption in the $\mathrm{UK}^{58}$ and Finland. ${ }^{59}$ Wide-spread implementation of such population strategies could be instrumental in delaying or preventing deaths from noncommunicable diseases including $\mathrm{CVD}^{60}$ and utilisation of a metric such as the IDHI could be useful in both appropriately targeting diet-related polices to geographic/ demographic subgroups, as well as in baseline and longitudinal assessments of the impacts of diet-related policies. For example, given that IDHI $_{\text {adverse }}$ is largest among men aged 20-44 in Colombia, public health officials may consider targeted efforts to reduce consumption of SSBs and sodium-rich foods in this population, and given that IDHI $_{\text {beneficial }}$ is smallest in over 70 age group in Zimbabwe, it could be useful to create policies that subsidise consumption of fruits, vegetables, nuts and seeds, whole grains and seafood (as a source of omega-3) among ageing adults. If such policies were to be implemented, evaluation of the IDHI in these populations before and after the interventions could be a useful metric of assessment. 
Our study has several strengths. Methodologically, unlike HEI and other dietary quality indices, IDHI is not based on predetermined dietary patterns; dietary factors were selected based on existing epidemiological evidence on their relationship to cardiometabolic health. Dietary quality indices usually have cut-off values for each dietary component for scoring; instead, we used the original dietary intake from each country-age-sex group in IDHIs. Prior investigations of dietary quality scores have highlighted the difficulty of assigning the relative contribution of each dietary component to an overall score ${ }^{61}$; here we used an evidence-based approach by weighting each dietary intake by the established aetiological effect of each component on corresponding disease outcomes. The IDHI further includes the cardiometabolic disease profile of each country-age-sex group such that the overall index reflects differences in disease backgrounds across populations. Moreover, our methodology is flexible and modifiable such that it can include additional dietary factors and diseases to assess the dietary impact on chronic diseases and undernutrition, as further data become available. Data on dietary intakes and outcomes were from large well-established studies; analyses were conducted at the country-age-sex level, the finest stratification of data available. Data on diet-disease relationships were from meta-analyses of large trials and observational studies and were evaluated for probable or convincing evidence based on Bradford Hill criteria. In keeping with evidence from prior work,${ }^{13}$ we developed the IDHI separately for overall, beneficial and adverse dietary effects. The IDHI provides a novel and efficient means for policymakers to evaluate the effects of overall diet, dietary subtypes and individual components of diet in the context of overall diet, on cardiometabolic health at the country and regional level.

Limitations of our approach should also be noted. First, the IDHIs were calculated from a subset of dietary factors that do not necessarily capture the totality of diet. The current analysis included six risk-reducing dietary factors and five risk-increasing factors; however, we used the best currently available data on dietary intakes, and the method is sufficiently flexible to incorporate additional components in the future. The IDHI ${ }_{\text {overall }}$ should be interpreted with caution, since countries with nearzero IDHI $_{\text {overall }}$ may either have equally large diet-related adverse and beneficial effects that 'cancel out', leading to a neutral IDHI ${ }_{\text {overall }}$, or they may have equally small adverse and beneficial effects that 'cancel out'. Therefore, the magnitude of the IDHI ${ }_{\text {overall }}$ does not necessarily fully reflect the magnitude of adverse or beneficial dietary effects, which are more clearly captured in the separate $\mathrm{IDHI}_{\text {adverse }}$ and $\mathrm{IDHI}_{\text {beneficial }}$ values. The magnitude of the IDHI $_{\text {overall }}$ is also affected by how many adverse versus beneficial dietary factors are included in the index, as well as their relative effects on health and the number of diet-disease pairs that can be included in the index reflects the availability of epidemiological evidence on dietary impacts on health. Therefore, future iterations of IDHI $_{\text {overall }}$ that include additional dietary factors must carefully evaluate and discuss the calibration of the index to ensure its meaningful interpretation. In general, the IDHI overall $_{\text {is }}$ useful in representing the 'net' effect of diet on health in a population, given available evidence, and initial inspection of the IDHI verall warrants subsequent detailed assessment of both the $\mathrm{IDHI}_{\text {beneficial }}$ and IDHI $\mathrm{Idverse}$. Additionally, we assessed the dietary impact on 12 cardiometabolic diseases, while in many low-income and middle-income countries, populations are facing joint burdens of cardiometabolic diseases and undernutrition. Future efforts will involve extending our methodology to capture the dietary impacts on this double burden. Data on diet-disease relationships were obtained, in part, from large prospective cohort studies, and as a result, the possibility of residual confounding cannot be eliminated; however, these aetiological effects have been validated previously ${ }^{24}$ and used in a number of large studies. 3033346263

In conclusion, we have developed and implemented a novel index to comprehensively evaluate overall dietary impact on 12 cardiometabolic diseases in 186 countries by age and sex, incorporating background cardiometabolic disease profile of each population. Our results indicate significant heterogeneity by geographic region, country income level, age and sex, indicating the importance of targeting policies and interventions to specific populations. However, we note that overall, across populations, diet has a net adverse effect on cardiometabolic health worldwide, indicating that the harms from unhealthful foods may be outweighing the beneficial effects of healthful foods and highlighting the need for large-scale global improvements to the food supply in order to increase the availability of healthful foods and limit production of and accessibility to unhealthy foods.

Contributors WAM and GMS developed the study concept and designed the study. JW cleaned data, performed index calculation and summarised results. YB provided technical support on index calculation. DM led the Global Dietary Database data collection efforts for dietary exposures and aetiological effects and provided conceptual input on index development. ENN provided mathematical insight on index calculation and interpretation. JW and GMS drafted the paper. All authors contributed to critical revision of the manuscript and have read and approved the final manuscript. The results have been presented, in part, as a poster at the 2018 American Society for Nutrition annual meeting in Boston, Massachusetts.

Funding GMS and JW were funded by a grant from the National Heart, Lung, and Blood Institute (ROOHL124321).

Competing interests DM reports research funding from the National Institutes of Health and the Gates Foundation; personal fees from GOED, Nutrition Impact, Pollock Communications, Bunge, Indigo Agriculture, Amarin, Acasti Pharma, Cleveland Clinic Foundation, America's Test Kitchen and Danone; scientific advisory board, Elysium Health, Filcitrine, Omada Health and DayTwo; and chapter royalties from UpToDate; all outside the submitted work. Other authors have nothing to disclose.

Patient and public involvement Patients and/or the public were not involved in the design, or conduct, or reporting, or dissemination plans of this research.

Patient consent for publication Not required.

Provenance and peer review Not commissioned; externally peer reviewed.

Data availability statement Data are available in a public, open access repository. All the data used in the study are publicly available. Please find Global Dietary Database at https://www.globaldietarydatabase.org/data-download, the 
Non-communicable Disease Risk Factor Collaboration at http://ncdrisc.org/datadownloads.html, the Global Health Data Exchange at http://ghdx.healthdata.org/ gbd-results-tool and the age-specific relative risk data at https://journals.plos.org/ plosone/article?id=10.1371/journal.pone. 0175149 and https://journals.plos.org/ plosone/article?id=10.1371/journal.pone.0065174.

Open access This is an open access article distributed in accordance with the Creative Commons Attribution Non Commercial (CC BY-NC 4.0) license, which permits others to distribute, remix, adapt, build upon this work non-commercially, and license their derivative works on different terms, provided the original work is properly cited, appropriate credit is given, any changes made indicated, and the use is non-commercial. See: http://creativecommons.org/licenses/by-nc/4.0/.

ORCID iD

Jifan Wang http://orcid.org/0000-0001-9720-8913

\section{REFERENCES}

1 World Health Organization. Cardiovascular diseases (CVDs): World Health organization, 2017. Available: https://www.who.int/en/newsroom/fact-sheets/detail/cardiovascular-diseases-(cvds) [Accessed 17 May 2019].

2 World Health Organization. Diabetes: World Health organization, 2018. Available: https://www.who.int/en/news-room/fact-sheets/ detail/diabetes [Accessed 17 May 2019].

3 Lim SS, Vos T, Flaxman AD, et al. A comparative risk assessment of burden of disease and injury attributable to 67 risk factors and risk factor clusters in 21 regions, 1990-2010: a systematic analysis for the global burden of disease study 2010. Lancet 2012;380:2224-60.

4 Kennedy ET, Ohls J, Carlson S, et al. The healthy eating index: design and applications. J Am Diet Assoc 1995;95:1103-8.

5 Chiuve SE, Fung TT, Rimm EB, et al. Alternative dietary indices both strongly predict risk of chronic disease. J Nutr 2012;142:1009-18.

6 Trichopoulou A, Kouris-Blazos A, Wahlqvist ML, et al. Diet and overall survival in elderly people. BMJ 1995;311:1457-60.

7 Trichopoulou A, Costacou T, Bamia C, et al. Adherence to a Mediterranean diet and survival in a Greek population. N Engl J Med 2003;348:2599-608

8 Fung TT, Rexrode KM, Mantzoros CS, et al. Mediterranean diet and incidence of and mortality from coronary heart disease and stroke in women. Circulation 2009;119:1093-100.

9 van Staveren WA, de Groot LCPMG, Haveman-Nies A. The SENECA study: potentials and problems in relating diet to survival over 10 years. Public Health Nutr 2002;5:901-5.

10 Martínez-González MA, Fernández-Jarne E, Serrano-Martínez M, et al. Mediterranean diet and reduction in the risk of a first acute myocardial infarction: an operational healthy dietary score. Eur $J$ Nutr 2002;41:153-60.

11 Serra-Majem L, Ribas L, Ngo J, et al. Food, youth and the Mediterranean diet in Spain. development of KIDMED, Mediterranean diet quality index in children and adolescents. Public Health Nutr 2004;7:931-5.

12 Kim S, Haines PS, Siega-Riz AM, et al. The diet quality IndexInternational (DQI-I) provides an effective tool for cross-national comparison of diet quality as illustrated by China and the United States. J Nutr 2003;133:3476-84.

13 Imamura F, Micha R, Khatibzadeh S, et al. Dietary quality among men and women in 187 countries in 1990 and 2010: a systematic assessment. Lancet Glob Health 2015;3:e132-42.

14 Miller LJ, Lu W. These are the world's healthiest nations: Bloomberg, 2019. Available: https://www.bloomberg.com/news/articles/201902-24/spain-tops-italy-as-world-s-healthiest-nation-while-u-s-slips [Accessed 6May 2019].

15 United Nations Development Programme. Health index: United nations development programme, 2013. Available: http://hdr.undp. org/en/content/health-index [Accessed 7 May 2019].

16 Grebmer Kvon, Bernstein J, Patterson F, et al. 2018 global hunger index forced migration and hunger. Dublin / Bonn: Welthungerhilfe, Concern Worldwide, 2018.

17 Rosenbloom JI, Kaluski DN, Berry EM. A global nutritional index. Food Nutr Bull 2008;29:266-77.

18 GBD 2017 Risk Factor Collaborators. Global, regional, and national comparative risk assessment of 84 behavioural, environmental and occupational, and metabolic risks or clusters of risks for 195 countries and territories, 1990-2017: a systematic analysis for the global burden of disease study 2017. Lancet 2018;392:1923-94.

19 GBD 2015 Risk Factors Collaborators. Global, regional, and national comparative risk assessment of 79 behavioural, environmental and occupational, and metabolic risks or clusters of risks, 1990-2015: a systematic analysis for the global burden of disease study 2015 . Lancet 2016:388:1659-724.

20 GBD 2017 Diet Collaborators. Health effects of dietary risks in 195 countries, 1990-2017: a systematic analysis for the global burden of disease study 2017. Lancet 2019;393:1958-72.

21 Wang DD, Li Y, Afshin A, et al. Global improvement in dietary quality could lead to substantial reduction in premature death. J Nutr 2019;149:1065-74

22 Sezaki A, Imai T, Miyamoto K, et al. Mediterranean diet score and incidence of IHD: a global comparative study. Public Health Nutr 2019;22:1444-50.

23 The Global Dietary Database 2010 [Internet]. Gerald J. and Dorothy R. Friedman School of Nutrition Science and Policy at Tufts University, 2010. Available: https://www.globaldietarydatabase.org/ data-download [Accessed 15 Mar 2019].

24 Micha R, Shulkin ML, Peñalvo JL, et al. Etiologic effects and optimal intakes of foods and nutrients for risk of cardiovascular diseases and diabetes: systematic reviews and meta-analyses from the nutrition and chronic diseases expert group (NutriCoDE). PLoS One 2017;12:e0175149.

25 Singh GM, Danaei G, Farzadfar F, et al. The age-specific quantitative effects of metabolic risk factors on cardiovascular diseases and diabetes: a pooled analysis. PLoS One 2013;8:e65174.

26 Data Downloads. Ncd risk factor collaboration, 2017. Available: http://ncdrisc.org/data-downloads.html [Accessed 19 Apr 2019]

27 . GBD Results Tool. Global health data exchange, 2019. Available: http://ghdx.healthdata.org/gbd-results-tool [Accessed 15 Mar 2019].

28 Micha R, Khatibzadeh S, Shi P, et al. Global, regional and national consumption of major food groups in 1990 and 2010: a systematic analysis including 266 country-specific nutrition surveys worldwide. BMJ Open 2015;5:e008705.

29 Khatibzadeh S, Saheb Kashaf M, Micha R, et al. A global database of food and nutrient consumption. Bull World Health Organ 2016;94:931-4.

30 Mozaffarian D, Fahimi S, Singh GM, et al. Global sodium consumption and death from cardiovascular causes. N Engl J Med 2014;371:624-34.

31 Global Dietary Database. Geographic regions: Tufts University, Gerald J. and Dorothy R. Friedman school of nutrition science and policy at Tufts university; n.d. Available: https://www.globaldietar ydatabase.org/our-data/data-available-request/geographic-regions [Accessed 21 Mar 2019].

32 The World Bank. World bank country and lending groups - world bank data help desk: the world bank group; n.d. Available: https:// datahelpdesk.worldbank.org/knowledgebase/articles/906519 [Accessed 20 Mar 2019].

33 Singh GM, Micha R, Khatibzadeh S, et al. Estimated global, regional, and national disease burdens related to sugar-sweetened beverage consumption in 2010. Circulation 2015;132:639-66.

34 Wang Q, Afshin A, Yakoob MY, et al. Impact of nonoptimal intakes of saturated, polyunsaturated, and trans fat on global burdens of coronary heart disease. J Am Heart Assoc 2016;5.

35 Willett W, Rockström J, Loken B, et al. Food in the Anthropocene: the EAT-Lancet Commission on healthy diets from sustainable food systems. Lancet 2019;393:447-92.

36 Tydeman-Edwards R, Van Rooyen FC, Walsh CM. Obesity, undernutrition and the double burden of malnutrition in the urban and rural southern free state, South Africa. Heliyon 2018:4:e00983.

37 Modjadji P, Madiba S. The double burden of malnutrition in a rural health and demographic surveillance system site in South Africa: a study of primary schoolchildren and their mothers. BMC Public Health 2019;19:1087.

38 Popkin BM. Global nutrition dynamics: the world is shifting rapidly toward a diet linked with noncommunicable diseases. Am J Clin Nutr 2006;84:289-98

39 Popkin BM. The shift in stages of the nutrition transition in the developing world differs from past experiences! Public Health Nutr 2002;5:205-14.

40 Popkin BM, Adair LS, Ng SW. Global nutrition transition and the pandemic of obesity in developing countries. Nutr Rev 2012;70:3-21.

41 Popkin BM. Nutrition transition and the global diabetes epidemic. Curr Diab Rep 2015;15:8.

42 Danaei G, Singh GM, Paciorek CJ, et al. The global cardiovascular risk transition: associations of four metabolic risk factors with national income, urbanization, and Western diet in 1980 and 2008. Circulation 2013;127:1493-502.

43 Masters WA, Hall A, Martinez EM, et al. The nutrition transition and agricultural transformation: a Preston curve approach. Agric Econ 2016;47:97-114. 
44 Lin TK, Teymourian Y, Tursini MS. The effect of sugar and processed food imports on the prevalence of overweight and obesity in 172 countries. Global Health 2018;14:35.

45 Stuckler D, McKee M, Ebrahim S, et al. Manufacturing epidemics: the role of global producers in increased consumption of unhealthy commodities including processed foods, alcohol, and tobacco. PLoS Med 2012;9:e1001235.

46 Basu S, McKee M, Galea G, et al. Relationship of soft drink consumption to global overweight, obesity, and diabetes: a cross-national analysis of 75 countries. Am J Public Health 2013;103:2071-7.

47 Pan A, Malik VS, Hu FB. Exporting diabetes mellitus to Asia: the impact of western-style fast food. Circulation 2012;126:163-5.

48 Vandevijvere S, Jaacks LM, Monteiro CA, et al. Global trends in ultraprocessed food and drink product sales and their association with adult body mass index trajectories. Obes Rev 2019;20 Suppl 2:10-19.

49 Singh GM, Micha R, Khatibzadeh S, et al. Global, regional, and national consumption of sugar-sweetened beverages, fruit juices, and milk: a systematic assessment of beverage intake in 187 countries. PLoS One 2015;10:e0124845.

50 Nogueira Bezerra I, de Carvalho Gurgel AO, Bastos Barbosa RG, et al. Dietary behaviors among young and older adults in Brazil. J Nutr Health Aging 2018;22:575-80.

51 Locher JL, Ritchie CS, Roth DL, et al. Food choice among homebound older adults: motivations and perceived barriers. J Nutr Health Aging 2009;13:659-64.

52 World Health Organization. Ncd global monitoring framework: World Health organization; n.d. Available: https://www.who.int/nmh/global monitoring_framework/en/ [Accessed 28 Jun 2019].

53 Colchero MA, Rivera-Dommarco J, Popkin BM, et al. In Mexico, evidence of sustained consumer response two years after implementing a sugar-sweetened beverage Tax. Health Aff 2017;36:564-71.

54 Lee MM, Falbe J, Schillinger D, et al. Sugar-Sweetened beverage consumption 3 years after the Berkeley, California, sugar-sweetened beverage Tax. Am J Public Health 2019;109:637-9.

55 Alvarado M, Unwin N, Sharp SJ, et al. Assessing the impact of the Barbados sugar-sweetened beverage tax on beverage sales: an observational study. Int J Behav Nutr Phys Act 2019;16:13.
56 Nakamura R, Mirelman AJ, Cuadrado C, et al. Evaluating the 2014 sugar-sweetened beverage Tax in Chile: an observational study in urban areas. PLoS Med 2018;15:e1002596.

57 Taillie LS, Rivera JA, Popkin BM, et al. Do high vs. low purchasers respond differently to a nonessential energy-dense food tax? Twoyear evaluation of Mexico's 8\% nonessential food tax. Prev Med 2017;105S:S37-42.

58 He FJ, Brinsden HC, MacGregor GA. Salt reduction in the United Kingdom: a successful experiment in public health. J Hum Hypertens 2014;28:345-52.

59 Pietinen P, Männistö S, Valsta LM, et al. Nutrition policy in Finland. Public Health Nutr 2010;13:901-6.

60 Kontis V, Cobb LK, Mathers CD, et al. Three public health interventions could save 94 million lives in 25 years global impact assessment analysis. Circulation;140:715-25.

61 Waijers PMCM, Feskens EJM, Ocké MC. A critical review of predefined diet quality scores. Br J Nutr 2007;97:219-31.

62 Afshin A, Micha R, Khatibzadeh S, et al. The impact of dietary habits and metabolic risk factors on cardiovascular and diabetes mortality in countries of the middle East and North Africa in 2010: a comparative risk assessment analysis. BMJ Open 2015;5:e006385

63 Yakoob MY, Micha R, Khatibzadeh S, et al. Impact of dietary and metabolic risk factors on cardiovascular and diabetes mortality in South Asia: analysis from the 2010 global burden of disease study. Am J Public Health 2016;106:2113-25.

64 Ezzati M, Bentham J, Di Cesare M, et al. Worldwide trends in body mass index, underweight, overweight, and obesity from 1975 to 2016: a pooled analysis of 2416 population-based measurement studies in 128.9 million children, adolescents, and adults. Lancet 2017;390:2627-42

65 Zhou B, Bentham J, Di Cesare M, et al. Worldwide trends in blood pressure from 1975 to 2015: a pooled analysis of 1479 populationbased measurement studies with 19.1 million participants. Lancet 2017;389:37-55.

66 Global Burden of Disease Study 2010 (GBD 2010) Population Estimates 1970-2010 [Internet], 2010. Available: http://ghdx. healthdata.org/record/global-burden-disease-study-2010-gbd-2010population-estimates-1970-2010 [Accessed 15 Mar 2019]. 